\section{$\therefore$ \\ Histogenesis of Primary Motor Area of Fetal Cerebrum}

IJCRR

Section: Healthcare ISI Impact Factor (2019-20): 1.628

IC Value (2019): 90.81 $\operatorname{SJIF}(2020)=7.893$

\section{Pandian Muthuchitra ${ }^{1}$, Sabnis Anjali ${ }^{2}$, Shroff Gautam ${ }^{3}$}

'PhD Scholar, MGM Institute of Health Sciences 410209, India; '2Professor and Head, Department of Anatomy, MGM Medical College, Navi Mumbai, India; ${ }^{3}$ Professor and Head, Department of Anatomy, MGM Medical College, Aurangabad, India.

\title{
ABSTRACT
}

Introduction: Histogenesis of the fetal cerebrum can be useful in the treatment of Lisencephaly, Cerebral hypoplasia, Polymicrogyria and heterotopias which are sex-linked inherited disorders using the Targeted Drug Delivery system by Nanoparticles in in-utero in future. In the present study, we had measured the thickness of the cortical plate of the motor area in micrometre using Image J software.

Aim: To study the thickness and number of layers in the primary motor area of the fetal cerebrum in different gestational ages.

Material and Methods: Hundred cerebral hemispheres obtained from 50 fetal cerebrums were collected. These brains were obtained from fetuses ranging from the $17^{\text {th }}$ week to the $40^{\text {th }}$ week. The study was authorized by the Ethical Committee for Analysis of Research Projects. Cortical thickness of the motor area of both sides of the cerebrum was measured by Image $\mathrm{J}$ software after doing routine $\mathrm{H} \& \mathrm{E}$ stains. The number of layers was identified in different gestational ages of human fetuses.

Results: The cortical thickness of the right motor area from $17^{\text {th }}$ week to $40^{\text {th }}$ week was $106.83-2298.19$ micrometre and the left motor areas were from $111.14-2330.37$ micrometre. At the $17^{\text {th }}$ week, 3 layers were observed. $20^{\text {th }}$ week 4 layers were observed, $22^{\text {nd }}$ week 5 layers were observed and from $24^{\text {th }}$ week onwards all the 6 layers were observed.

Conclusion: The number of layers and cortical thickness increases with the increasing gestational age. By birth, the cerebral cortical thickness is approximately $2 \mathrm{~mm}$.

Key Words: Fetal cerebrum, Histogenesis, Cortical thickness, Lamination, Motor area, Gestational age

\section{INTRODUCTION}

The primary motor area of the cerebrum is of immense importance as it deals with motor control of the whole body. The histologically primary motor area is composed of six layers in adults. This complex structure of the primary motor area of an adult human cerebrum is formed from the fetal cerebrum through cellular proliferation, differentiation and migration. Histogenesis of the cerebral cortex (neocortex) The layered structure of the adult cerebral cortex forms from the telencephalon as the surface area increases. At first, there are 3 zones to the cortex: 1) germinal zone, immediately surrounding the lateral ventricle, 2) intermediate zone, which becomes the white matter, and 3) marginal zone, which becomes the grey matter. ${ }^{1}$ Neuroblast of the germinal zone divides and migrate into the marginal zone to become neurons and glial cells. ${ }^{1}$ The marginal zone is formed by cells migrating a) early, which become the deeper layers of the cortex while those that migrate b) later, form the more superficial layers. ${ }^{1}$ The neocortex represents the great majority of the cerebral cortex. It has six layers and contains between 10 and 14 billion neurons. The six layers of this part of the cortex are numbered with Roman numerals from superficial to deep. ${ }^{1}$ Layer I is the molecular layer, which contains very few neurons; layer II is the external granular layer; layer III is the external pyramidal layer; layer IV is the internal granular layer; layer V is the internal pyramidal layer, and layer VI is the multiform, or fusiform layer. ${ }^{1}$ Each cortical layer contains different neuronal shapes, sizes and densities as well as different organizations of nerve fibres. The cerebral cortex is the outer covering of grey matter over the hemispheres. ${ }^{1}$ It is typically 2- $3 \mathrm{~mm}$ thick, covering the gyri and sulci. ${ }^{2}$

Lamination is one of the hallmarks of the cerebral cortex. ${ }^{3}$ Despite the early recognition of this characteristic feature of cortical histology there is still little understanding of the

\section{Corresponding Author:}

Dr. Sabnis Anjali, Professor and Head, Department of Anatomy, MGM Medical College, Navi Mumbai, India. Email: dranjus2003@yahoo.com

ISSN: $2231-2196$ (Print)

Received: 01.01 .2021
ISSN: 0975-5241 (Online)

Revised: 12.03 .2021
Accepted: 03.05 .2021
Published: 11.10 .2021 
fundamental organizing principle that governs it. ${ }^{4}$ It is not possible in the present state of the science to define the determinants of cortical cytoarchitecture". ${ }^{5}$ We have yet to achieve a universal theory of cortical organization. ${ }^{6}$ The motor cortex is an area of the frontal lobe located on the precentral gyrus that is involved in the planning, control, and execution of voluntary movement.

In the present study, we are concentrating on the development of the number of layers and cortical thickness of grey mater from $17^{\text {th }}$ week to the $40^{\text {th }}$ week of fetal gestational age.

\section{MATERIAL AND METHODS}

Hundred cerebral hemispheres from 50 fetuses ranging from $17^{\text {th }}$ week to $40^{\text {th }}$ week were collected from MGM Hospital after spontaneous abortions. After fixation of the fetal brain with formalin removal of brains was performed using a typical autopsy technique. The cerebrum was carefully removed from anterior to posterior by cutting the cranial nerves and spinal cord. Meninges were removed from the superolateral aspect of the cerebrum. The right and left cerebral hemispheres were separated by taking a cut on the corpus callosum. Inferior to the trunk of corpus extended the incision into the tela choroidea of the lateral and third ventricles, and the interthalamic adhesion connecting the medial surface of two thalami. The arachnoidal membranes and superficial vessels of the cerebral hemispheres were removed to simplify the identification of the sulci on the superolateral, medial and inferior cerebral surfaces. Fetal cerebral primary motor area tissues of both left and right sides were taken for block making and then for H/E stain. The development of layers and their cortical thickness in the primary motor area was observed and measured by image $\mathrm{J}$ software in a micrometre (Table- 1).

The data is taken from the research study for $\mathrm{PhD}$ on "comparative study of microanatomy of fetal cerebrum of normal and eclamptic mothers".

Table 1: Cortical thickness of fetal cerebral cortex of motor area from $17^{\text {th }}$ week to $40^{\text {th }}$ week in micrometre:

\begin{tabular}{lcccc} 
Weeks & \multicolumn{2}{c}{ RM (mean \& S.D) } & \multicolumn{2}{c}{ LM (mean \& S.D) } \\
17 & 106.83 & +-5.72 & 11.14 & +-5.83 \\
18 & 136.28 & +-6.57 & 148.24 & +-11.68 \\
19 & 264.52 & +-13.29 & 277.24 & +-11.08 \\
20 & 306.61 & +-12.49 & 314.15 & +-8.25 \\
21 & 337.46 & +-20.71 & 342.51 & +-19.17 \\
22 & 439.76 & +-26.83 & 443.86 & +-15.30 \\
23 & 513.96 & +-26.94 & 525.11 & +-29.57 \\
24 & 659.05 & +-23.99 & 671.99 & +-20.68
\end{tabular}

\section{Table 1: (Continued)}

\begin{tabular}{lccc} 
Weeks & RM (mean \& S.D $)$ & \multicolumn{2}{c}{ LM (mean \& S.D) } \\
25 & $729.3 \quad+-28.66$ & $740.4+-18.69$ \\
26 & $824.45+-56.72$ & $848.48+-34.01$ \\
27 & 871.94 & 907.8 \\
28 & $1071.19+-93.80$ & $1154.47+-145.79$ \\
29 & 1218.97 & 1299.76 \\
31 & 1361.91 & 1433.97 \\
34 & 1808.81 & 1895.3 \\
39 & 2116.11 & 2179.27 \\
40 & 2298.19 & 2330.37 \\
\hline
\end{tabular}

The study was authorized by the Ethical Committee for Analysis of Research Projects. Specimens with congenital malformations and or structural damage were excluded.

\section{RESULT}

The cortical thickness of the right motor area from $17^{\text {th }}$ week to $40^{\text {th }}$ week was $106.83-2298.19$ micrometre and the left motor area was from $111.14-2330.37$ micrometre. In statistical analysis mean and standard deviation was calculated. At the $17^{\text {th }}$ week, 3 layers were observed. The number of layers increased with increasing gestational age. $20^{\text {th }}$ week 4 layers were observed, $22^{\text {nd }}$ week 5 layers were observed and from $24^{\text {th }}$ week onwards all the 6 layers were observed.

\section{DISCUSSION}

In the present study on at $17^{\text {th }}$ week, there appeared 3 layers in the cortical plate (Figure-1A, Table-2).

\section{Table 2: Number of layers developed per week}

\begin{tabular}{lc} 
Weeks & Number of layers \\
$17^{\text {th }}$ & 3 \\
$18^{\text {th }}$ & 3 \\
$19^{\text {th }}$ & 3 \\
$20^{\text {th }}$ & 4 \\
$21^{\text {st }}$ & 4 \\
$22^{\text {nd }}$ & 5 \\
$23^{\text {rd }}$ & 5 \\
$24^{\text {th }}$ & 6 \\
$25^{\text {th }}$ & 6 \\
$27^{\text {th }}$ & 6 \\
$28^{\text {th }}$ & 6 \\
$29^{\text {th }}$ & 6 \\
$31^{\text {st }}$ & 6 \\
$34^{\text {th }}$ & 6 \\
$39^{\text {th }}$ & 6 \\
$40^{\text {th }}$ & 6 \\
\hline
\end{tabular}




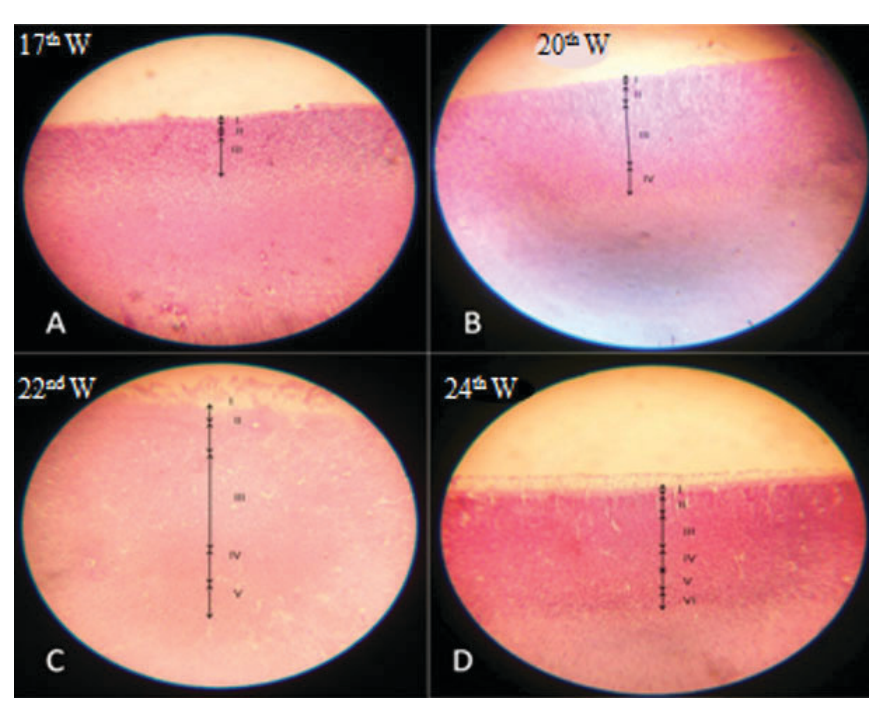

Figure 1: Development of layers increases according to increasing gestational age. A. 17th week; B. 20th week; C. 22nd week; D. 24th week.

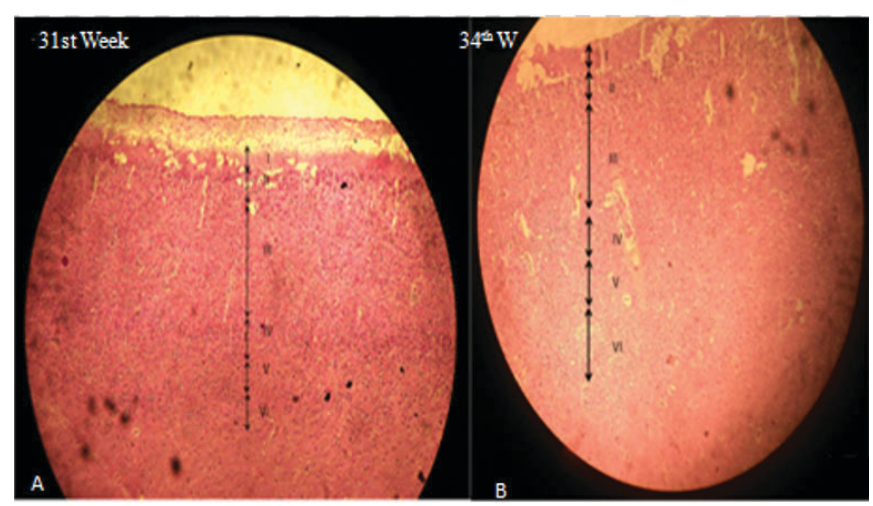

Figure 2: 31st week and 34th week fetal cerebral cortex showing six layers.

In layer I the cells are loosely packed and in layer III the cells are more tightly packed than layer II. At $20^{\text {th }}$ and $21^{\text {st }}$ weeks, 4 layers were seen (Fig. 1 B). In the book called "The development of the human neocortex," it is written that the cortical plate is undifferentiated at the $4^{\text {th }}$ and $5^{\text {th }}$ months of gestational age. ${ }^{7}$ In the present study 5 layers were observed at $22^{\text {nd }}$ and $23^{\text {rd }}$ week (Fig. $1 \mathrm{C}$ ) and from the $24^{\text {th }}$ week onwards all the 6 layers were seen in the cortical plate (Fig. $1 \mathrm{D})$. It was observed that from the $6^{\text {th }}$ month onwards all the 6 layers appeared in the cortical plate. ${ }^{7}$ Between 6 and 8 months 6 layers are observed in the marginal zone of the neocortex, recognized by cellular and fibre laminate. ${ }^{8}$ In the present study the $31^{\text {st }}$ and $34^{\text {th }}$ weeks show 6 layers in grey mater (Fig.2).

We had also measured the thickness of the cortical plate from the $17^{\text {th }}$ week to the $40^{\text {th }}$ week of both the right and left motor area of the fetal cerebral cortex. The cortical thickness was measured in micrometre by using image $\mathrm{J}$ software. The cortical thickness of the right motor area from the $17^{\text {th }}$ week to the $40^{\text {th }}$ week was $106.83-2298.19$ micrometre and the left motor area was from 111.14 - 2330.37 micrometre (Table-1). The mammalian cerebral cortex primordial cytoarchitectural organization goes through four sequential stages, which, in order of appearance, are: the undifferentiated neuroepithelium (NE), the marginal zone (MZ), the primordial plexiform (PP), and the PCP appearance. ${ }^{9}$ At $11^{\text {th }}$-week fetal cortical thickness is 115 micrometre. ${ }^{7}$ At $15^{\text {th }}$-week fetal cortical thickness is 350 micrometres. ${ }^{9}$ The starting functional maturation of the deepest and older pyramidal neurons of the grey matter (PCP) establishes the first functional pyramidal cell stratum in the human motor cortex, which should correspond to layer $\mathrm{V}$ of the current nomenclature. ${ }^{9}$ By stage 20 , the primordial plexiform lamina is well established, extends throughout the entire surface of the developing cerebral cortex, and is considered to be functionally active. It is, by this age, a superficial, $40 \mu \mathrm{m}$ thick, complex fibrillar neuronal organization composed of numerous horizontal corticipetal fibres (demonstrable with silver methods), horizontal-bipolar Cajal-Retzius neurons and a few other, less defined, cellular elements. ${ }^{10}$

In the present study, the right motor area of the $20^{\text {th }}$ week was 306.61 micrometre and the left motor area was $314.15 \mathrm{mi}-$ crometre. It was observed that at the $20^{\text {th }}$ week the length of the pyramidal neuron of stratum P1 is already 450 micrometers. ${ }^{9}$ The motor cortex grey matter thicknesses, including differentiated and undifferentiated pyramidal neurons, ranges between 400 and 600 micrometers. ${ }^{9}$ In the present study the right motor area of the $34^{\text {th }}$ week was 1808.81 micrometre and the left motor area was 1895.3 micrometre. It was observed that at the $35^{\text {th }}$ week the thickness of the motor area cortex grey mater ranges between 700 and 900 micrometres. ${ }^{9}$ In the present study the right motor area of the $40^{\text {th }}$ week was 2298.19 micrometre and the left motor area was 2330.37 micrometre. The newborn primary cortex motor, already about $2 \mathrm{~mm}$ thick, is characterized by the abundance of pyramidal neurons. ${ }^{9}$ At birth, the human motor cortex grey matter thickness ranges from 1,500 to 1,700 micrometres. $^{9}$

Before 28 gestational weeks the cortical plate was anechoic and a discrete layer from the underlying anechoic subplate zone, it was, therefore, inconspicuous on the sonographic image. ${ }^{11}$ Any fetal CNS anomalies like Lissencephaly, intracranial haemorrhage, severe ventriculomegaly, microcephaly etc shows abnormal cerebral lamination. ${ }^{11}$ Abnormal lamination will lead to abnormal migration of neurons which will, in turn, disturb the normal function of the brain.

\section{CONCLUSION}

The cortical thickness and number of layers in the primary motor area increases with the gestational age of the fetus on 
both sides. The proliferation of cells may increase the cortical thickness and number of layers in the primary motor area. Knowledge of thickness in the primary motor area may be useful to judge the thickness of the primary motor area of a newborn child in preterm delivery. This information may help to identify gestational lag while scanning fetuses of intrauterine growth retardation.

\section{ACKNOWLEDGEMENT}

1. Professor and head, OBGY Department, MGM Medical College, Dr. Sushil Kumar for permitting to collect fetuses from MGM Kalamboli hospital.

2. Dr. Atul Deshmukh for helping us with using Image $\mathbf{J}$ software for measuring the cortical thickness.

\section{Conflicts of Interests: NIL}

\section{Source of funding: NIL}

\section{Contribution of authors:}

1. Dr. Pandian R. Muthuchitra ${ }^{1}$ : Receiving and dissecting a fetal brain, making blocks and staining of slides, compiling data and statistical analysis.

2. Dr. Sabnis S. Anjali²: Interpretation of results and writing the article.

3. Dr. Shroff A. Gautam ${ }^{3}$ : Helped to get fetuses from OBGY department and interpretation of results.

\section{REFERENCES}

1. Malcolm B. carpenter, A.B. M.D. Neuroanatomy $4^{\text {th }}$ edition. London Williams \& Wilkins. Pg 390-391.

2. Williams PL, Warwick R (eds): Gray's Anatomy. Philadelphia: Saunders, $37^{\text {th }}$ ed. Churchill Livingstone 1989. Pg. 1044.

3. Braitenberg V cortical architectonics general and aerial. In: Brazier MAB, Petsche H (eds) Architectonics of the cerebral cortex. Raven, New York, 1978; 443- 465.

4. Jone E. laminar distribution of cortical efferents cells. In: Peter A, Jones (eds) cerebral cortex, vol 1. Plenum Press, New York, 1984; 521-553.

5. Jones EG. Determinants of the cytoarchitecture of the cerebral cortex. In: Edelman GM, Gall WE, Cowan WM (eds) Signal and sense: local and global order in perceptual maps. Wiley, New York, 1990; 3-49.

6. Rakic P, Singer W., Introduction. In: Rakic P, Singer W (eds) Neurobiology of the neocortex, report of the Dahlem workshop. Wiley, Berlin, 1988; 1-4.

7. Altman J, Bayer S. Development of the human neocortex" A review and interpretation of the histological records, the laboratory of developmental neurobiology. Inc Ocala. 34481, USA 2015.

8. Haldar A, Sahoo S, Chakraborty S, Banerjee P, Basu D. Cellular migration and histogenesis of the cerebral cortex with functional correlations in human fetuses at different weeks of gestation Int J Med Res. 2019;4(1): 51-54.

9. Marín-Padilla M. The human brain, prenatal development and structure. Springer-Verlag Berlin Heidelberg. 2011.

10. Miguel MP. Structural organization of the human cerebral cortex before the appearance of the cortical plate. Anat Embry. 1983;16(8): 21-40

11. Pugash D, Hendson G, Dunham CP, Dewar K, Moneys K, Prayer D. Sonographic assessment of normal and abnormal patterns of fetal cerebral lamination. Ultras Obstetgy. 2012; 40: 642-651. 